\title{
p27Kipl Localizes to Detergent-insoluble Microdomains Within Lymphocyte Membranes
}

\author{
Beatrice B. Yaroslavskiy,, Donna B. Stolz, ${ }^{2}$ Simon C. Watkins, ${ }^{2}$ Sean M. Alber, ${ }^{2}$ \\ Neil A. Bradbury ${ }^{2}$ and Richard A. Steinman ${ }^{1}$ \\ Departments of ${ }^{1}$ Medicine and ${ }^{2}$ Cell Biology and Physiology, University of Pittsburgh \\ School of Medicine, Pittsburgh, Pennsylvania, U.S.A. \\ Accepted September 25, 2000.
}

\begin{abstract}
Background: Low levels of the cyclin-dependent kinase inhibitor p27Kipl are associated with poor prognosis in cancer. It is unclear whether this is related strictly to p27Kipl-mediated cell cycle inhibition or to other, possibly extranuclear, roles of this protein. In this study, we examined p27Kipl expression in quiescent and activated lymphocytes. T-cell membranes have been shown to possess sphingolipid and cholesterol-rich microdomains that are insoluble in non-ionic detergents. These "rafts" provide a scaffold for signaling proteins. Signal transduction coincides with coalescence of these microdomains into larger complexes.
\end{abstract}

Methods: Localization of p27Kipl was studied by electron and confocal microscopy. Association of p27Kipl with membrane microdomains in unstimulated and stimulated lymphocytes was determined using Western blots analysis of isolated membranes variably treated with detergents.

Results: We demonstrated that p27Kipl was present in clusters associated with the plasma membrane in normal lymphocytes. The solubility profile of p27Kipl in isolated membranes indicated that it was localized to raft structures. When lymphocytes were stimulated, however, p27Kipl was excluded from aggregated raft complexes.

Conclusions: This study identifies, for the first time, the localization of p27 within a membrane microdomain associated with signaling. Because some cell surface signaling complexes lose p27Kipl upon cellular activation, p27Kipl may play a functional role in modulating membrane signaling.

\section{Introduction}

p27Kipl is a cyclin-dependent kinase inhibitor (cdki) that mediates growth arrest of cells in the setting of serum-deprivation or cell-to-cell contact. Interest in p27Kipl function has been heightened by the finding that a low level of p27 is a negative prognostic indicator in many cancers, including colon, breast, and lymphoma (1-4). In recent years, p27 functions distinct from growth arrest have been revealed, including inhibition $(5,6)$ or promotion (7) of apoptosis, transcriptional modulation (8), induction of cell migration (9), promotion of clonal anergy (8), and differentiation (10-12).

Several studies indicate that, in addition to total p27 levels, the subcellular localization of p27 may modulate p27 function. Whereas, p27 is nuclear in quiescent myeloid precursor cells, it accumulates in the cytoplasm of these cells following cytokine activation (13). Cytoplasmic expression of p27 also

Address correspondence and reprint requests to: Richard A. Steinman, M.D., Ph.D., E1052 Biomedical Science Tower, University of Pittsburgh, 200 Lothrop Street, Pittsburgh, PA 15213, U.S.A. Phone: 412-624-4627; Fax: 412-624-7794; Steinman@imap.pitt.edu has been reported in esophageal, ovarian (14), and colorectal cancers $(15,16)$. Sequestration of p27 into cytoplasmic complexes with cyclin D3 prevents p27-mediated growth arrest $(17,18)$.

p27 has been shown to sustain resting T lymphocytes in the quiescent state (19). Mitogenic activation of lymphocytes is associated with a decrease in p27 protein levels (19) and with increased localization of p27 to the cytoplasm (20). It recently was demonstrated that lymphocyte activation depended on the clustering of $26 \mathrm{~nm}$ (21) sphingolipid and cholesterolrich structures within the membrane, known as rafts (22). These microdomains within the membrane are characterized by insolubility in non-ionic detergents (23). Interventions that prevent raft clustering (24) or that interfere with protein localization into raft domains (25) prevent cell activation. We now report our finding that a subpopulation of p27 is present in membrane rafts in normal human lymphocytes.

\section{Materials and Methods Cell Preparation}

Peripheral blood lymphocytes were obtained from healthy volunteers in accordance with an Insti- 
tutional Review Board (IRB)-approved protocol. Mononuclear cells were isolated from peripheral blood by density gradient centrifugation over Ficoll Hypaque (1.077 g/ml, Sigma, St. Louis, MO). Peripheral blood mononuclear cells (PBMC) were allowed to adhere overnight on a $75 \mathrm{~cm}^{2}$ tissue culture flask in the presence of (RPMI) medium containing $10 \%$ fetal bovine serum (FBS; Life Technologies, Grand Island, NY) and lacking cytokines. Lymphocyte-enriched, nonadherent cells were used in this study. $60-75 \%$ of cells were routinely positive for the CD3 T-cell marker upon fluorescence-activated cell sorting (FACScan) analysis of nonadherent cells.

\section{Confocal Microscopy}

Confocal microscopy for p27 was performed using a Leica (TCS-NT) confocal microscope (Leica, Deerfield, IL) as previously described (13). In brief, I million cells were washed in phosphate-buffered saline (PBS) containing $2 \%$ FBS and $0.5 \%$ azide (washing buffer), fixed with $1 \%$ paraformaldehyde, suspended in $75 \%$ cold ethanol and stored at $-20^{\circ} \mathrm{C}$. Fixed cells were permeabilized with $0.25 \%$ Triton $\mathrm{X}-100$ and $40 \mu \mathrm{g} / \mathrm{ml}$ digitonin for $5 \mathrm{~min}$, washed and blocked with $1 \%$ bovine serum albumin (BSA). Cells were then incubated with monoclonal antip27 antibody (Labvision, Fremont, CA) at 1:50 dilution followed by Alexa 488 conjugated goat antimouse antibody for $1 \mathrm{hr}$ (1:500 dilution, Molecular Probes, Eugene OR). Following immunostaining, a drop of cell suspension was placed onto charged coverslips mounted within the microscope. Each scan averaged four sequential scans through the mid-plane of the cells. In some experiments, cells were permeabilized with Triton X-100 without fixation, as indicated in the text.

Triton X-100-permeabilized cells were doublestained for p27 and for CD59 as follows: nonadherent PBMC were incubated on ice with $1 \%$ Triton $X$ 100 in PBS for 10 min and, subsequently, washed in washing buffer and stained with phycoerythrin (PE)-conjugated anti-CD59 antibody (1:25 dilution; Pharmingen, San Diego, CA) for $20 \mathrm{~min}$ on ice, washed, and fixed with $2 \%$ paraformaldehyde. Cells were then treated with Triton X-100 and digitonin as above. Cells were washed in a mixture of $2 \%$ human serum and $2 \%$ goat serum in $1 \%$ BSA, and then incubated for $15 \mathrm{~min}$ in $2 \%$ goat serum in $1 \%$ BSA to block nonspecific binding. The cells were then stained for p27 using either immunoglobulin G (IgG; negative control) or rabbit anti-p27 (Santa Cruz Biotechnology, Santa Cruz, CA), followed by goat anti-rabbit Cy5 (Jackson Immunoresearch Lab, West Grove, PA).

Crosslinking of CD59 and double-staining of cells for CD59 and for p27 was performed as follows: nonadherent PBMC were stained with mouse monoclonal anti-CD59 (1:25 dilution, 20 min on ice; Pharmingen) followed by flourescein isothiocyanate
(FITC)-conjugated goat-anti-mouse IgG (1:10 dilution, 30 min on ice; Caltag). The cells were then incubated at $37^{\circ} \mathrm{C}$ for $1 \mathrm{hr}$, washed, fixed with $2 \%$ paraformaldehyde, and blocked. They then were stained with IgG (negative control) or with rabbit anti-p27, followed by alexa-594-conjugated antirabbit secondary antibody (Molecular Probes, Eugene, OR).

Specificity of p27 staining was confirmed by con- focal micrography of lymphocytes stained with rabbit anti-p27 antibody that was preincubated either with nonspecific peptide (p73 epitope) or with peptide specific to the p27 antibody (p27 epitope). The latter prevented staining; whereas, the former did not (data not shown).

\section{Cellular Fractionation}

60-100 million cells were suspended in ice-cold hypotonic buffer at $5 \times$ the packed cell volume and immediately centrifuged at $3000 \mathrm{rpm}$ and resuspended in hypotonic buffer at $10 \times$ the packed cell volume for 10 min with periodic vortexing. Cell permeabilization over time was followed in aliquots by measuring dye exclusion using trypan blue. Nuclei were pelleted at $3000 \mathrm{rpm}$ for $15 \mathrm{~min}$. The membrane component of the post-nuclear fraction was isolated by centrifugation at $100,000 \times \mathrm{g}$ for $1 \mathrm{hr}$. This pellet was washed in hypotonic buffer and the dry pellet was suspended in $2 \times$ sodium dodecylsulfate (SDS) sample buffer for Western blots analysis.

\section{Plasma Membrane Isolation Using Cationic Colloidal Silica}

Purified plasma membranes were isolated from 30 million lymphocytes using slight modifications of protocols described in detail previously (26). Cells were washed in $5 \mathrm{ml}$, then resuspended in $1 \mathrm{ml}$ MES-buffered saline (MBS): $20 \mathrm{mM} \mathrm{2(N-}$ morpholino)-ethanesulfonic acid (MES) $150 \mathrm{mM}$ $\mathrm{NaCl}, \mathrm{pH}$ 5] prior to adding them dropwise to $3 \mathrm{ml}$ of $1 \%$ cationic colloidal silica in MBS [Cationic colloidal silica prepared as described by (27), available to interested researchers from D.B.S.]. Silica-coated cells were diluted to $10 \mathrm{ml}$ in MBS, pelleted, washed in MBS, then resuspended in $1 \mathrm{ml}$ MBS prior to adding them dropwise to polyanion solution $[1 \mathrm{mg} / \mathrm{ml}$ polyacrylic acid (molecular weight 240,000 kDa; Aldrich, St. Louis, MO) in MBS]. Cells were diluted to $10 \mathrm{ml}$ MBS, pelleted, washed in MBS, then quickly washed in a small volume of lysis buffer [LB; $10 \mathrm{mM} \mathrm{N}$-2-hydroxyethylpiperazine$\mathrm{N}$-2-ethanesulfonic acid (HEPES), pH 7.9, $1.5 \mathrm{mM}$ $\mathrm{MgCl} 2,10 \mathrm{mM} \mathrm{KCl}$ containing the following broad spectrum protease inhibitors: $10 \mu \mathrm{g} / \mathrm{ml}$ pepstatin, leupeptin, E64; $1 \mathrm{mM}$ sodium orthovanadate, and phenylmethylsulfonyl fluoride (PMSF)]. Cells were resuspended in $1 \mathrm{ml} \mathrm{LB}$ and incubated on ice for $30 \mathrm{~min}$. Coated cells were lysed by 100 strokes in a Dounce homogenizer with a close-fitting pestle. Lysed cells were layered onto a cushion of $350 \mu \mathrm{l}$ 
$70 \%$ Nycodenz (Gibco/BRL, solubilized in LB) and sedimented at $20,000 \times \mathrm{g}$ in a $4^{\circ} \mathrm{C}$ microfuge for $30 \mathrm{~min}$. Silica-coated membranes sediment through the Nycodenz cushion to form a tight, glassy pellet. Noncoated membranes remain at the Nycodenz-lysis buffer interface, and soluble proteins remain in the LB. Pellets were resuspended and washed in LB. Plasma membrane proteins were removed from silica by resuspension in $2 \%$ SDS in LB, followed by probe sonication (Branson Sonifier), then boiled for $5 \mathrm{~min}$. Silica was removed from the suspension by centrifugation at $14,000 \times \mathrm{g}$ for $15 \mathrm{~min}$, proteins remained in the supernatant and were used for Western blots analysis.

\section{Extract Treatment}

Extracts from lymphocytes were prepared as follows: 30 million lymphocytes washed in PBS were centrifuged at $1000 \times \mathrm{g}$ at $4^{\circ} \mathrm{C}$, resuspended in $5 \times$ the pellet volume in hypotonic buffer [10 mM HEPES, ph 7.9, $1.5 \mathrm{mM} \mathrm{MgCl2,} 10 \mathrm{mM} \mathrm{KCl}, 0.2 \mathrm{mM}$ PMSF, $1 \%$ protease inhibitor cocktail (Sigma)], and incubated on ice for $30 \mathrm{~min}$. An equal volume of $2 \%$ Triton X-100 was added to indicated tubes prior to $4^{\circ} \mathrm{C}$ incubation. Cells were then pelleted in a cold microcentrifuge $(10,000 \mathrm{rpm})$ for $20 \mathrm{~min}$, washed in hypotonic buffer, and repelleted. As indicated, an octylglucoside buffer $(60 \mathrm{mM} 60 \mathrm{mM}$ N-octyl $\beta$ D-glucopyranoside $10 \mathrm{mM}$ HEPES- $\mathrm{NaCl}, 150 \mathrm{mM}$ $\mathrm{NaCl}, \mathrm{pH} 7.4,0.1 \%$ SDS; all reagents from Sigma) was added to the Triton-insoluble pellet for an additional $30 \mathrm{~min}$ on ice, then debris was again pelleted for $20 \mathrm{~min}$ at $10,000 \mathrm{rpm}$. Supernatents and insoluble pellets were separately dissolved in $2 \mathrm{X}$ SDS sample buffer (4\% SDS, $100 \mathrm{mM}$ Tris, $\mathrm{pH} 6.8$, $200 \mathrm{mM}$ dithiothreital, $20 \%$ glycerol), boiled for $5 \mathrm{~min}$, and loaded on a $12.5 \%$ SDS-PAGE gel for analysis.

Plasma membrane pellets isolated using colloidal silica were analyzed for detergent solubility. The membrane pellet was solubilized in Nonidet P-40 (NP-40) buffer (0.5\% NP-40, 50 mM Tris$\mathrm{HCl}, \mathrm{pH} 7.5,150 \mathrm{mM} \mathrm{NaCl}, 50 \mathrm{mM} \mathrm{NaF}$ ) on ice for 60 min. Following NP-40 incubation, samples were centrifuged at $14,000 \mathrm{rpm}$ at $4^{\circ} \mathrm{C}$ for $10 \mathrm{~min}$, supernatent was removed for analysis (NP-40-soluble fraction), and the dry pellet was suspended in SDS sample buffer for loading on SDS-PAGE gels (NP40-insoluble fraction).

\section{Western Blots Analysis}

Western blots analysis was performed on cell extracts fractionated on $12.5 \%$ SDS-PAGE using standard techniques. Antibodies used included horseradish peroxide (HRP)-conjugated p27 antibody (Transduction Laboratories, San Diego, CA), mouse monoclonal anti-caveolin (Transduction Laboratories), monoclonal anti-tubulin (Labvision), and monoclonal (PCNA; Santa Cruz Biotechnology, Santa Cruz, CA).

\section{Immunoelectron Microscopy (IEM)}

Cells were processed for IEM as described previously (28). Monoclonal anti-p27 (1:100; Labvision) or rabbit anti-human p27 (1:40; Santa Cruz, Biotechnology, Santa Cruz, CA) were used as the primary antibodies, followed by $5 \mathrm{~nm}$ gold-conjugated species-appropriate secondary antibodies directed to either mouse or rabbit (Auroprobe, Amersham, Arlington Heights, IL).

\section{Results}

\section{Clustering of p27Kipl at the Plasma Membrane}

We previously reported changes in the ratio of cytoplasmic/nuclear p27 concurrent with activation of myeloid cells and lymphocytes $(13,20)$. While following up that work, we imaged perpheral blood lymphocytes using immuno-electron microscopy. This revealed the presence of multiple clusters of p27 immunoreactivity abutting the plasma membrane (Fig. 1). Similar findings were obtained with several lymphocyte preparations, using both murine monoclonal and rabbit polyclonal p27 antibodies (data not shown). Membrane-associated p27 was confirmed by Western blots analysis of membrane extracts prepared as a S-100 pellet using standard subcellular fractionation techniques (Fig. 2).

\section{Membrane-bound p27 was Concentrated} in Triton-insoluble Microdomains

We then analyzed the solubility of membraneassociated p27 in non-ionic detergents. A number of T-cell signaling pathways involve proteins that are localized in membrane microdomains, which are insoluble in non-ionic detergents (29). These domains aggregate upon cellular activation and promote the colocalization of glycophosphoinositol (GPI)-linked proteins and src family tyrosine kinases, such as fyn and lck (30).

Solubilization of lymphocytes in cold NP-40 for 30 min resulted in the loss of nuclear p27 on examination by confocal microscopy (Fig. 3). A rim of p27 remained in the membrane, however, suggesting decreased solubility of a membrane-associated portion of p27. Similar results to NP-40 were obtained with cold Triton X-100 incubation (data not shown).

Western blots analysis was undertaken to confirm whether p27 was present in detergent insoluble microdomains of lymphocytes, as suggested by the imaging studies above. Plasma membranes were isolated from lymphocytes and their p27 content was determined after exposure to various detergents. Both quiescent lymphocytes and lymphocytes activated for $20 \mathrm{hr}$ with phorbol ester 12-O-tetradecanoylphorbol-13-acetate (PMA) plus phytohemagglutinin (PHA) were studied. Results are shown in Figure 4A. Total cellular p27 obtained by directly lysing cells in SDS loading buffer are shown in lanes 1 and 5. Plasma membrane fractions were isolated in parallel using silica bead membrane 

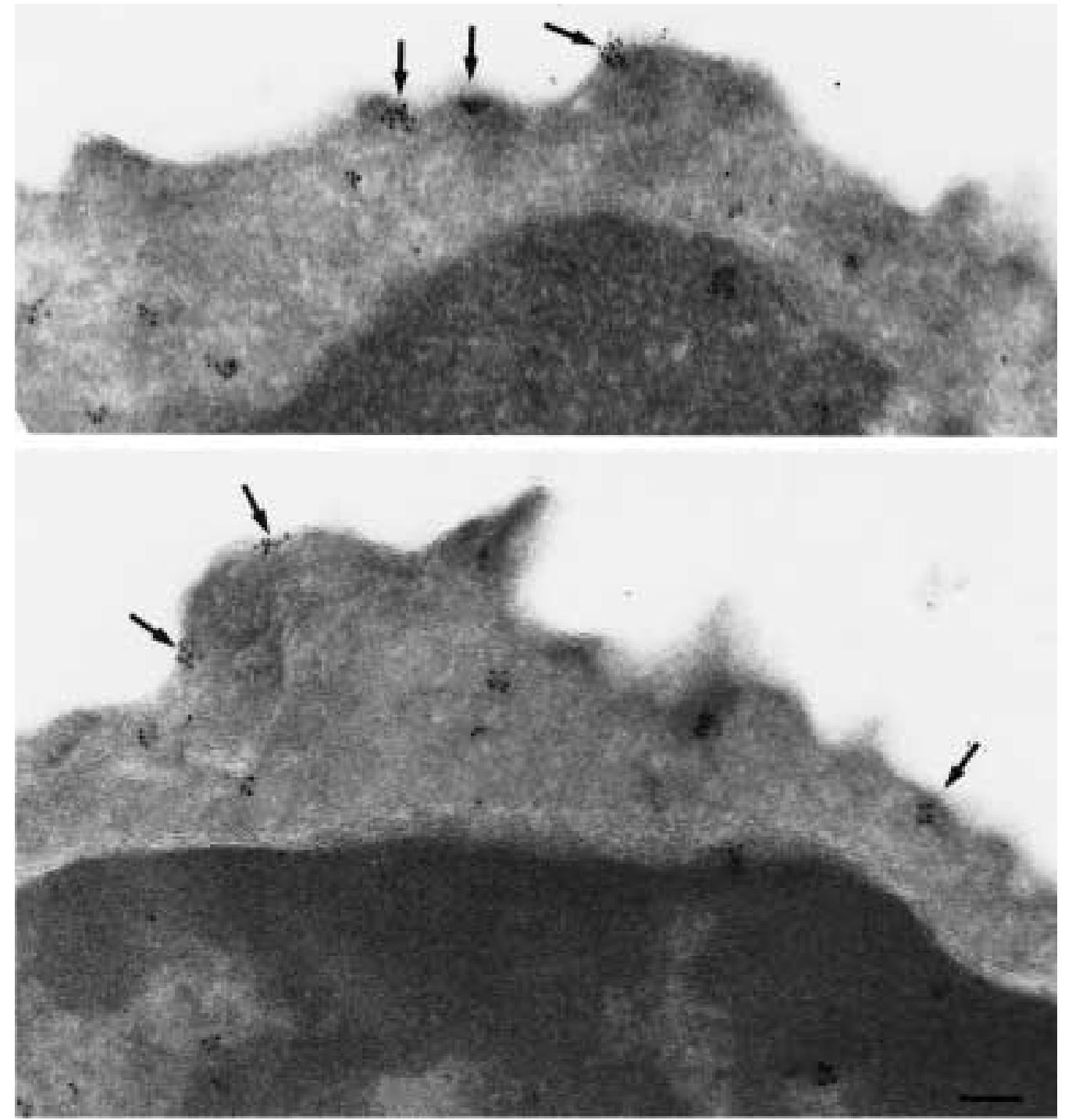

Fig. 1. Electron microscopy of p27 in normal lymphocytes. Freshly harvested lymphocytes were processed for immunoelecton microscopy and stained with polyclonal anti-p27 antibodies. Two representative cells are shown. Clusters of p27 associated with the plasma membrane are indicated by arrows. Bar $=100 \mathrm{~nm}$.

stripping techniques. The membrane fractions were first solubilized in $0.5 \%$ cold NP-40 for $30 \mathrm{~min}$, and the supernatent was removed for Western blots analysis (lanes 3 and 7). The NP-40-insoluble pellet then was washed and dissolved in SDS sample buffer. p27 immunoreactivity within the detergentinsoluble membrane fraction is shown in lanes 4 and 8. When comparing detergent solubility of p27, it was evident that the 30 -min incubation in cold NP40 was incapable of solubilizing membrane p27; whereas, the p27-containing pellet was soluble in SDS buffer. In addition to full-length p27, a 22-kD p27 immunoreactive form is faintly visible in NP40-resistant membrane fraction. The amount of p27 present in insoluble complexes in the membrane decreased proportionately with total p27 upon cellular activation.
The src family protein, lck, was roughly $50 \%$ solubilized by NP-40, compatible with previous reports (31). The insoluble lck dissolved in SDS buffer. Unlike p27, actin was not detected in the membrane fraction of lymphocytes prepared by this method. Figure $4 \mathrm{~A}$ also demonstrates that the GPI-microdomain associated protein, caveolin 1 , is absent in lymphocytes, a finding consistant with previous reports (32).

We then tested whether nonionic detergentinsoluble p27 could be released from microdomains by octylglucoside. The detergent octylglucoside is effective at solubilizing proteins embedded in membrane microdomains, because it chemically resembles gangliosides and disrupts sphingolipidcholesterol rich complexes $(33,34)$. If p27 was strongly associated with a detergent-insoluble 


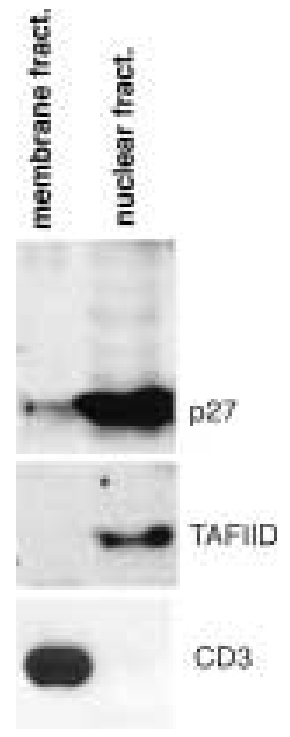

Fig. 2. Western blots of isolated membrane. Lymphocytemembrane fraction isolated as an S-100 pellet (membrane) and isolated nuclei were stained for p27. They are also stained with fractionation controls, TAFIID (a nuclear transcription factor) and the CD3 $\mathrm{T}$ cell surface marker, as indicated.

sphigolipid-rich membrane domain, then octylglucoside should have rendered it soluble. Figure 4B shows the results obtained when lymphocytes were incubated in cold $1 \%$ Triton X-100 for $30 \mathrm{~min}$. A portion of p27 remained in the Triton-insoluble pellet, despite repeated washings with lysis buffer. Subsequent addition of $60 \mathrm{mM}$ octylglucoside completely solubilized the p27. These results support the likelihood that p27 can associate with proteins localized into detergent-insoluble membrane microdomains in lymphocytes.

\section{p27 Did Not Co-aggregate with CD59} upon Lymphocyte Activation

We examined whether p27 co-localized with CD59, a GPI-linked glycoprotein, which is a constituent of membrane rafts in $\mathrm{T}$ cells (30). Lymphocytes were treated for 10 min with cold Triton X-100 and washed to remove detergent-soluble proteins. They

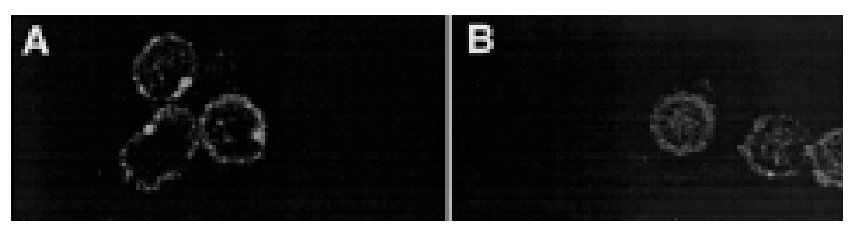

Fig. 3. p27 expression in detergent-treated lymphocytes. Freshly harvested peripheral blood lymphocytes were incubated in cold buffer containing $0.5 \%$ NP-40 (A) or buffer lacking NP40 (B) for $30 \mathrm{~min}$, washed, fixed, permeabilized, and stained in suspension for p27 expression. Confocal images acquired at equal (pmt) sensitivity are shown. Membrane, but not nuclear expression of p27, persists after NP-40. then were double-stained for expression of CD59 and p27. As Figure 5A demonstrates, both p27 (red) and CD59 (green) remained after detergent treatment. Areas of overlap (yellow color) in the expression of p27 and CD59 are apparent in most of these unstimulated cells.

CD59 activation initiates T-cell signaling leading to interleukin-2 (IL-2) production and proliferation $(35,36)$. Janes et al. (31) demonstrated that cross-linking of CD59 results triggered aggregation of rafts into large complexes and recruitment of the T-cell receptor (TCR) into those CD59-containing complexes. Such aggregation of rafts into large patches occurs in response to diverse activation stimuli, which recruit TCR into the vicinity of src-tyrosine kinases $(37,38)$. We stimulated $\mathrm{T}$ cells as described by Janes et al. (31) by crosslinking CD59 with anti-CD59 antibody, followed by FITCconjugated anti-mouse IgG secondary antibody, and then warming the cells for $1 \mathrm{hr}$ at $37^{\circ} \mathrm{C}$. Cells then were fixed and stained for p27 expression (red). As shown in Figure 5B, CD59 (green) was aggregated into discrete membrane patches by this approach. p27 stained prominently in the cytoplasm and membrane. It was notable that p27 did not form patches with CD59. This was manifested by the lack of patching evident in the p27 window, and by the absence of yellow (which would signal p27 and CD59 colocalization) in the overlapped view.

\section{p27 was Excluded from CD69-containing Patches upon Lymphocyte Activation}

If the exclusion of p27 from aggregated signaling complexes was physiologically significant, it should have occurred in response to multiple stimuli, and not just to antibody crosslinking. We investigated whether p27 in lipid rafts would be excluded from patches formed upon lymphocyte stimulation with the mitogenic combination of phytohemagglutinin (PHA) and phorbol ester 12O-tetradecanoylphorbol-13-acetate (PMA). Unstimulated and mitogen-stimulated lymphocytes were incubated with DiOC16(3), a fluorescent lipid analogue that stains late endosomes and surface membrane (39). These analogues have been shown to sort preferentially to lipid rafts (40). The cells also were double-stained with phycoerythrocinconjugated CD69, and with anti-p27 antibody and a Cy5-conjugated secondary antibody. Results are shown in Figure 6. Several points are notable. p27 is expressed discontinuously along the membrane. Areas of overlap with DiOC16(3) appear as white; whereas, membrane free of p27 appears as green (DIOC16/p27 column). It also was evident that CD69 was up-regulated by mitogens and accumulated in membrane patches. These patches appear yellow in the three-color overlay as a result of overlapping DIOC16(3) and CD69. Notably, p27 is excluded from these patches (Fig. 6, columns 2, 4, and 5). 

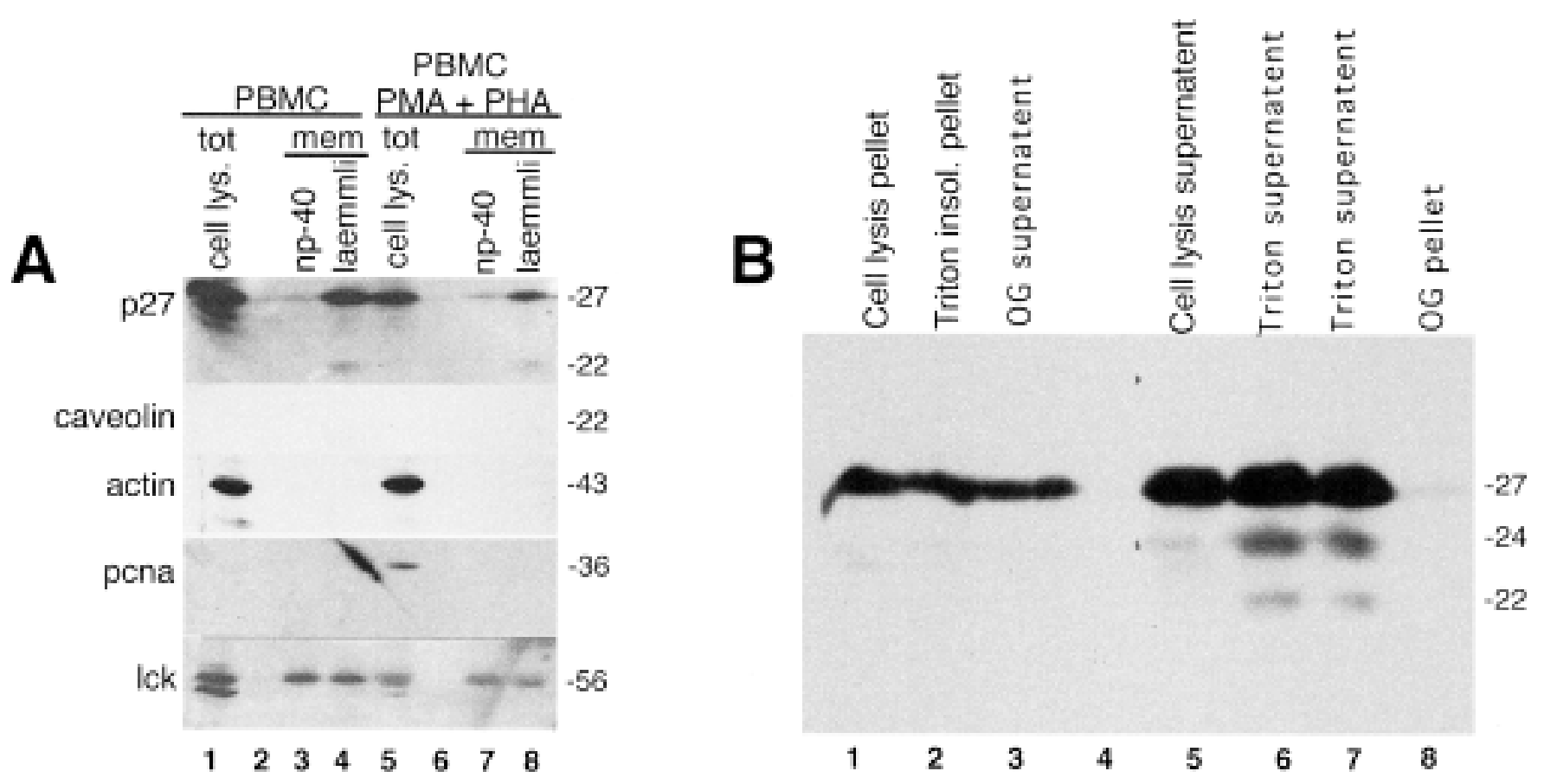

Fig. 4. Presence of p27 in detergent-insoluble membrane domains. (A) Insolubility of p27 in NP-40. Western blots analysis of nonadherent peripheral blood mononuclear cells (PBMC) or PBMC activated for $24 \mathrm{hr}$ in $100 \mathrm{nM}$ phorbol ester 12-Otetradecanoylphorbol-13-acetate (PMA) and $1 \mu \mathrm{g} / \mathrm{ml}$ phytohemagglutinin (PHA). Expression of proteins in total cell extracts (tot) and in membrane fractions prepared from an equivalent number of cells is shown. "NP-40" indicates the supernatent obtained after 60 min incubation in cold NP-40. The protein content of the insoluble NP-40 pellet was determined by dissolving that pellet in sodium dodecyl sulfate (SDS) buffer (laemmli). PCNA positivity indicates the activated status of the mitogen-exposed cells and that the nuclear fraction is not present in membrane preparations. Molecular weights are indicated in margins. (B) Insoluble p27 can be dissolved in octylglucoside. Western blots indicating p27 levels in the total cellular pellet after lysis in hypotonic buffer (lane 1) and in the pellet remaining after cells were incubated for $30 \mathrm{~min}$ in cold 1\% Triton X-100 (Triton insol., lane 2). The Triton-insoluble pellet subsequently was dissolved in cold octylglucoside (OG), as described in text, and solubilized p27 (OG-supernatent, lane 3), and remaining insoluble p27 (OG pellet, lane 8) determined. Rapidly migrating variants of p27, as seen in the Triton-soluble fractions (Triton supernatents, lanes 6,7 ) have been described elsewhere [Yaroslavskiy et al., submitted, and (51)].

\section{Discussion}

This paper reports the localization of the p27Kipl cell cycle inhibitor to specific plasma membrane domains in lymphocytes that are insoluble in nonionic detergents. This solubility profile characterizes glyosphingolipid- and cholesterol-rich islands in the membrane, which anchor GPI-linked proteins and are enriched in signaling proteins (22). The presence of p27 in such membrane domains, known as rafts (23), has not been described previously.

The mechanism through which p27 can associate with the plasma membrane is unclear. p27 itself lacks a signal sequence and does not contain acylation motifs. Similarly, established p27-binding partners, cdk2, cdk4, cyclins, and jab1, lack signal sequences and myristoylation or palmitoylation motifs. p27 also does not contain a clathrin box sequence through which clathrin-coated pits are bound $(41,42)$.

The finding that p27 is present in clusters associated with the plasma membrane indicate that p27 is likely to be localized into discrete micro- domains within the membrane, rather than associated in a random fashion. Another nuclear protein, engrailed, has been shown to localize to membrane microdomains enriched in cholesterol and glycosphingoglycolipids (43). However, unlike p27, this protein contains a sequence that renders it capable of transversing membranes. In our view, the most likely mechanism for p27 localization to the membrane in lymphocytes is through transport from the cytoplasm in complex with an acylated protein partner. p27 is evident in the cytoplasm of lymphocytes upon confocal microscopy. Cytoplasmic p27 exists in complexes with jabl (44) and with cyclin D3 (R.A.S., unpublished observations). The proportion of cytoplasmic p27 that is en route to or from the plasma membrane will require more investigation.

Analysis of the solubility profile of membraneassociated p27 indicates that it is insoluble in the nonionic detergents NP-40 and Triton X-100 at $4^{\circ} \mathrm{C}$, but could be dissolved by the spingolipid-like detergent octylglucoside. These results strongly support the likelihood that p27 is localized in "rafts," 

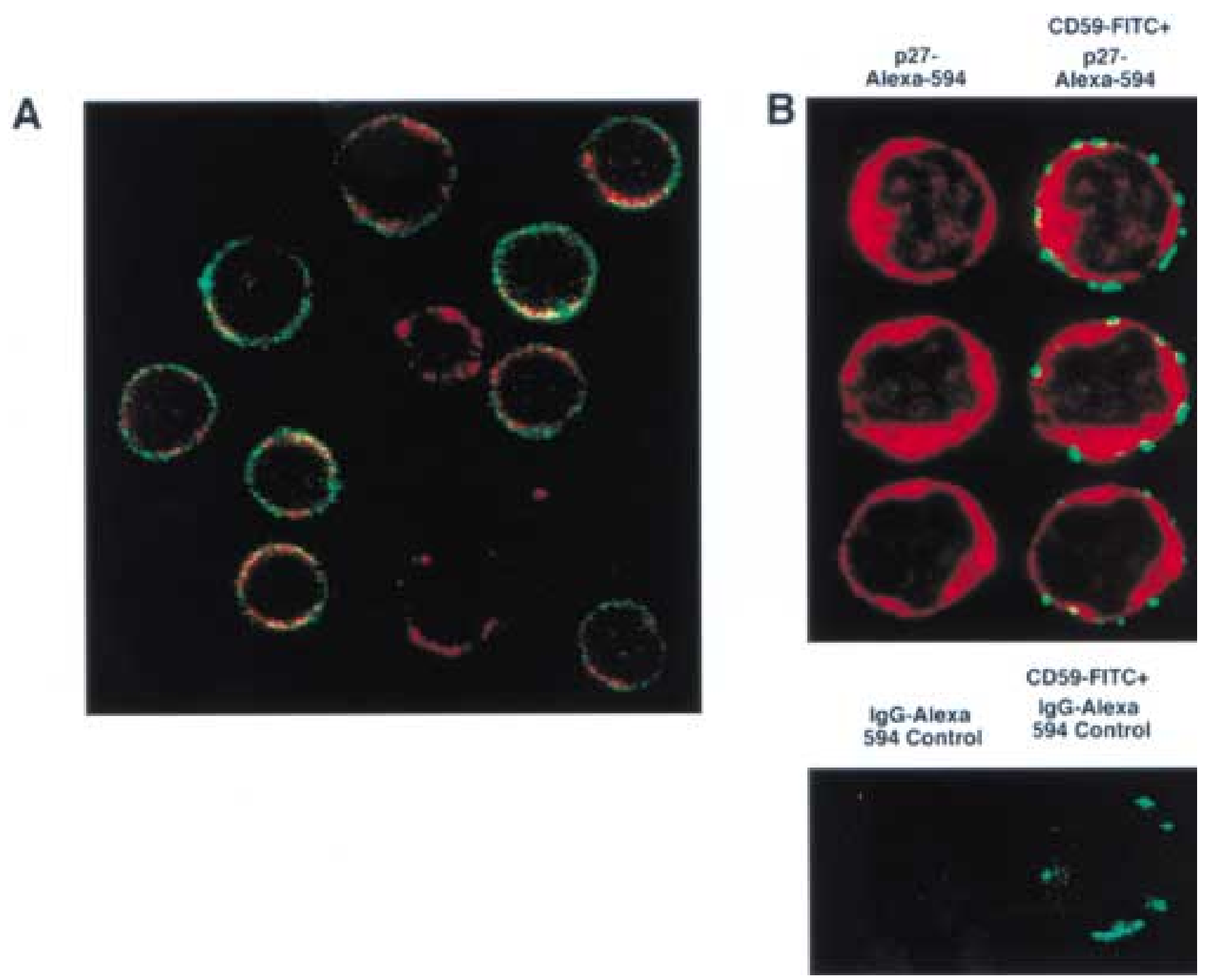

Fig. 5. Colocalization of p27 and CD59 in unstimulated but not in activated lymphocytes. (A) Overlapping of p27 and CD59 expression in Triton X-100 treated lymphocytes. Cells treated with Triton X-100 were stained directly with (PE)-Conjugated anti-CD59 and indirectly with anti-p27 as described in the text. Color channels were set so that CD59 appears green, p27 appears red, and overlap appears yellow. (B) Lack of aggregation of p27 in lymphocytes activated by CD59 crosslinking. Nonadherent peripheral blood mononuclear cells (PBMC) were activated with murine anti-CD59, crosslinking with anti-mouse immunoglobulin G-(IgG-FITC) and incubation at $37^{\circ} \mathrm{C}$. They subsequently were stained indirectly with p27 as described. p27 staining (red) and with CD59 staining (green) is shown for three representative cells. p27 staining (red) of the cells is shown in the left column. The right column shows the same cells, gated to reveal both p27 (red) and CD59 (green) staining. Control staining is shown below, performed as above, but using an isotype control IgG instead of anti-p27. Staining with isotype control for CD59 (not shown) was negative.

glycosphingolipid-cholesterol-rich microdomains in the lymphocyte membrane. Such domains are increasingly recognized to coordinate the topographic requirements for signaling complexes, and also organize the endocytic trafficking of GPI-anchored proteins bound at their surface. These detergentinsoluble microdomains have been shown to serve as platforms for signal transduction. By coalescing into a larger structure, rafts appear to integrate signals, promoting the formation of active signaling complexes. Among the signaling components that have been localized to detergent-insoluble membrane domains are nonreceptor tyrosine kinases, ras family proteins, heterotrimeric G-proteins (45), potassium channels (46), and serine-threonine kinase activities (47). Activation of the corresponding signaling path- ways requires redistribution of the raft domains into larger aggregates. In lymphocytes, aggregation of rafts is required for T-cell receptor signaling (29,31), leukocyte function-associated antigen-1 (LFA-1) mediated adhesion (48), and Bcell receptor signaling (49).

Although the distribution of p27 overlapped that of the raft component CD59 in unactivated cells, we note that p27 does not aggregate along with CD59 when cells are activated with anti-CD59 

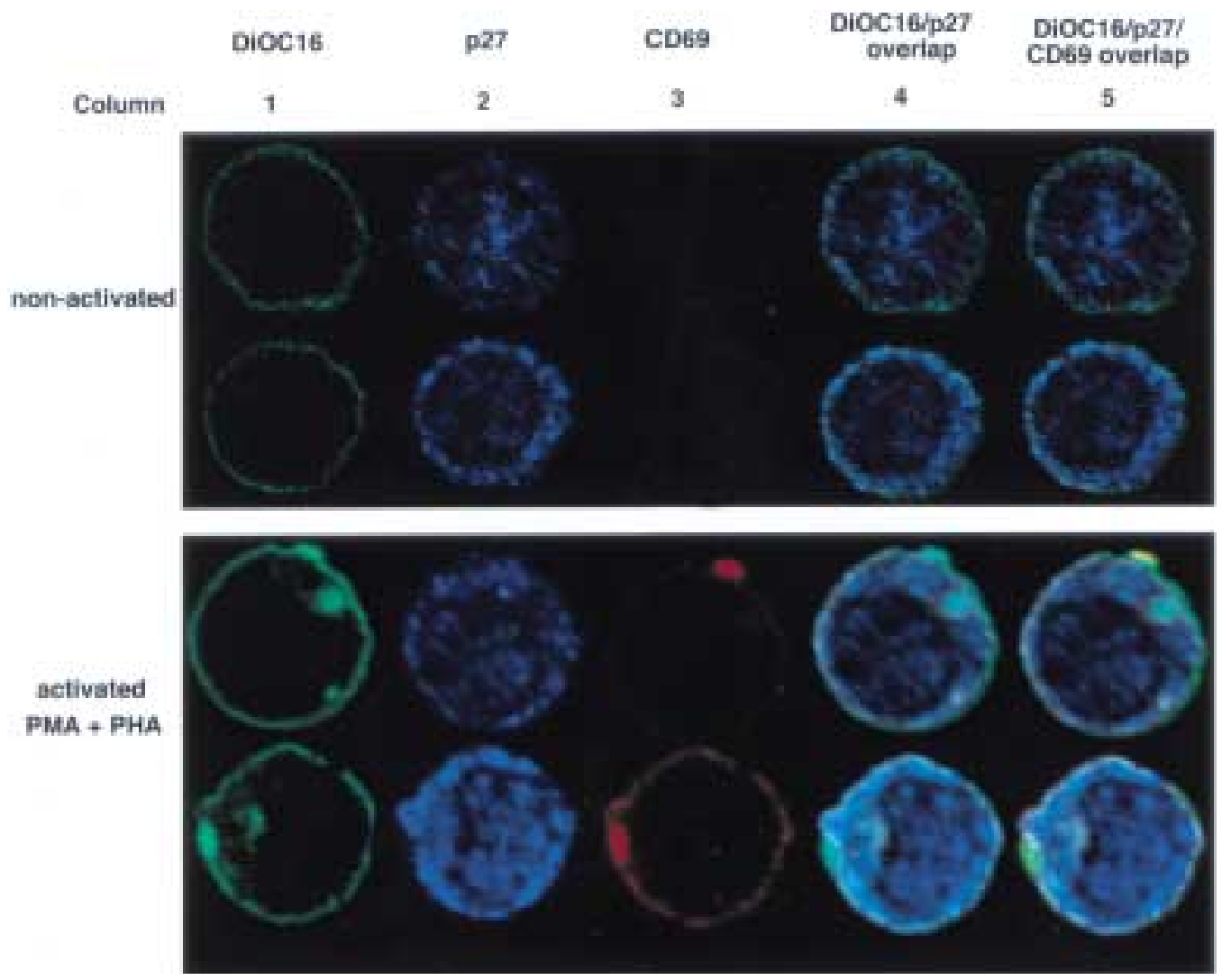

Fig. 6. Patching of CD69, but not of p27, upon mitogen stimulation of lymphocytes. Lymphocytes were incubated for 16 hr in the presence of medium alone (unactivated) or medium containing phorbol ester 12-O-tetradecanoylphorbol-13-acetate (PMA; 100 ng) and phytohemagglutinin (PHA; $1 \mu \mathrm{g} / \mathrm{ml}$ ), and stained for the lipid analogue DIOC16(3) (green), p27 (blue) or CD69 (red), as described in the text. Areas of overlap of DIOC16(3) and p27 appear as white (overlay in 4th column); overlap of CD69 and DIOC16 (3) are yellow.

antibody. Changes in the makeup of detergentresistant glycoprotein domains during aggregation have been reported in other systems. For instance, fatty acids caused the displacement of lck, but not of CD59, from aggregated domains (38). The distribution of p27 in the membrane is modulated during lymphocyteactivation. This is manifest by the specific exclusion of p27 from aggregated CD69expressing domains in mitogen-activated lymphocytes. Because two distinct mechanisms of lymphocyte activation lead to the formation of patches that lack a p27 component, our data suggests that the distribution of p27 in insoluble membrane domains is dynamic and nonrandom.

While this manuscript was under final preparation, Gaulin et al. (50) reported that cdk2 was present in the plasma membranes of rat liver parenchymal cells. Plasma membrane cdk2 exhibited high levels of kinase activity, which was inhibited by insulin. They further showed in a rat model that injection of the insulin-mimetic $\mathrm{bpV}$ (phen) led to recruitment of p27 into the cdk2 complex in plasma membranes in liver. Plasma membrane-associated p27 inhibits cdk2 kinase activity in these cells. In contrast, we were unable to detect cdk2 in complexes with p27 in the plasma membrane in unstimulated or stimulated lymphocytes. The report that p27 is present in liver cell membranes underscores the likelihood that the p27 membrane localization described in this paper is generalizable and physiologically relevant.

What is the significance of p27 localization to rafts within the plasma membrane? Because p27 is excluded when rafts aggregate into large signaling complexes, it is conceivable that p27 antagonized signaling. p27 could be a component of a complex that helps maintain lymphocytes in a basal state of quiescence. This could occur through inhibition of kinases, a function suggested for membraneassociated p27 in rat liver (50). Alternatively, the presence of p27 could forestall aggregation of raft complexes in quiescent cells. In a natural killer (NK) cell model, inhibition of raft aggregation by tumor cell major histocompatibility complex (MHC) receptors attenuated NK cell function (24). Future investigations should uncover whether p27 modulates raft-based signal transduction and, if so, whether this differs between normal and neoplastic cells. 


\section{Acknowledgements}

We thank Drs. Rebecca Hughey, Ora Weisz, and Candace Johnson for helpful discussions. We also thank Drs. Robert Getzenberg for TAFIID antibody, Penny Morel for lck antibody, and Rebecca Hughey for octylglucoside. This work was supported by a grant from the American Cancer Society (RPG-98083) to R.A.S.

\section{References}

1. Porter PL, Malone KE, Heagerty PJ, et al. (1997) Expression of cell-cycle regulators p27Kipl and cyclin E, alone and in combination, correlate with survival in young breast cancer patients [see comments]. Nat. Med. 3: 222-225.

2. Loda M, Cukor B, Tam SW, et al. (1997) Increased proteasome-dependent degradation of the cyclin-dependent kinase inhibitor p27 in aggressive colorectal carcinomas [see comments]. Nat. Med. 3: 231-234.

3. Lloyd RV, Erickson LA, Jin L, et al. (1999) p27kipl: a multifunctional cyclin-dependent kinase inhibitor with prognostic significance in human cancers. Am. J. Pathol. 154: 313- 323.

4. Erlanson M, Portin C, Linderholm B, Lindh J, Roos G, Landberg G. (1998) Expression of cyclin E and the cyclindependent kinase inhibitor p27 in malignant lymphomasprognostic implications. Blood 92: 770-777.

5. Wang J, Walsh K. (1996) Resistance to apoptosis conferred by Cdk inhibitors during myocyte differentiation. Science 273: 359-361.

6. Eymin B, Haugg M, Droin N, Sordet O, Dimanche-Boitrel MT, Solary E. (1999) p27Kipl induces drug resistance by preventing apoptosis upstream of cytochrome c release and procaspase-3 activation in leukemic cells. Oncogene 18: 14111418.

7. Katayose Y, Kim M, Rakkar AN, Li Z, Cowan KH, Seth P. (1997) Promoting apoptosis: a novel activity associated with the cyclin- dependent kinase inhibitor p27. Cancer Res. 57: 5441-5445.

8. Boussiotis VA, Freeman GJ, Taylor PA, et al. (2000) p27Kipl functions as an anergy factor inhibiting interleukin 2 transcription and clonal expansion of alloreactive human and mouse helper T lymphocytes. Nat. Med. 6: 290-297.

9. Nagahara H, Vocero-Akbani AM, Snyder EL, et al. (1998) Transduction of full-length TAT fusion proteins into mammalian cells: TAT-p27Kipl induces cell migration. Nat. Med. 4: 1449-1452.

10. Zabludoff SD, Csete M, Wagner R, Yu X, Wold BJ. (1998) p27Kipl is expressed transiently in developing myotomes and enhances myogenesis. Cell Growth Differ. 9: 1-11.

11. Hauser PJ, Agrawal D, Flanagan M, Pledger WJ. (1997) The role of p27Kipl in the in vitro differentiation of murine keratinocytes. Cell Growth Differ. 8: 203-211.

12. Kranenburg O, Scharnhorst V, Van der Eb AJ, Zantema A. (1995) Inhibition of cyclin-dependent kinase activity triggers neuronal differentiation of mouse neuroblastoma cells. J. Cell Biol. 131: 227-234.

13. Yaroslavskiy B, Watkins S, Donnenberg AD, Patton TJ, Steinman RA. (1999) Subcellular and cell-cycle expression profiles of CDK-inhibitors in normal differentiating myeloid cells. Blood 93: 2907-2917.

14. Masciullo V, Sgambato A, Pacilio C, et al. (1999) Frequent loss of expression of the cyclin-dependent kinase inhibitor p27 in epithelial ovarian cancer. Cancer Res. 59: 3790-3794.

15. Singh SP, Lipman J, Goldman H, et al. (1998) Loss or altered subcellular localization of p27 in Barrett's associated adenocarcinoma. Cancer Res. 58: 1730-1735.

16. Sgambato A, Ratto C, Faraglia B, et al. (1999) Reduced expression and altered subcellular localization of the cyclindependent kinase inhibitor p27(Kipl) in human colon cancer. Mol. Carcinog. 26: 172-179.
17. Baldassarre G, Belletti B, Bruni P, et al. (1999) Overexpressed cyclin D3 contributes to retaining the growth inhibitor p27 in the cytoplasm of thyroid tumor cells. J. Clin. Invest. 104: 865-874.

18. Sanchez-Beato M, Camacho FI, Martinez-Montero JC, et al. (1999) Anomalous high p27/KIP1 expression in a subset of aggressive B-cell lymphomas is associated with cyclin D3 overexpression. p27/KIP1-cyclin D3 colocalization in tumor cells. Blood 94: 765-772.

19. Nourse J, Firpo E, Flanagan WM, et al. (1994) Interleukin-2mediated elimination of the p27Kipl cyclin-dependent kinase inhibitor prevented by rapamycin. Nature 372: 570-573.

20. Yaroslavskiy B, Watkins S, Donnenberg AD, Steinman RA. (1998) Alteration in subcellular localization of p27KIP1 in mononuclear cells stimulated with SEB or IL-2. Blood 92: 374a.

21. Pralle A, Keller P, Florin E, Simons K, Horber JK. (2000) Sphingolipid-cholesterol rafts diffuse as small entities in the plasma membrane of mammalian cells [In Process Citation]. J. Cell Biol. 148: 997-1008.

22. Brown DA, London E. (2000) Structure and function of sphingolipid- and cholesterol-rich membrane rafts. J. Biol. Chem. In Press

23. Hooper NM. (1999) Detergent-insoluble glycosphingolipid/ cholesterol-rich membrane domains, lipid rafts and caveolae (review). Mol. Membr. Biol. 16: 145-156.

24. Lou Z, Jevremovic D, Billadeau DD, Leibson PJ. (2000) A balance between positive and negative signals in cytotoxic lymphocytes regulates the polarization of lipid rafts during the development of cell-mediated killing. J. Exp. Med. 191: 347-354.

25. Lin J, Weiss A, Finco TS. (1999) Localization of LAT in glycolipid-enriched microdomains is required for T cell activation. J. Biol. Chem. 274: 28861-28864.

26. Stolz DB, Jacobson BS. (1991) Macro- and microvascular endothelial cells in vitro: maintenance of biochemical heterogeneity despite loss of ultrastructural characteristics. In Vitro Cell. Dev. Biol. 27A: 169-182.

27. Chaney LK, Jacobson BS. (1983) Coating cells with colloidal silica for high yield isolation of plasma membrane sheets and identification of transmembrane proteins. J. Biol. Chem. 258: 10062-10072.

28. Rizzo MA, Shome K, Vasudevan C, et al. (1999) Phospholipase $\mathrm{D}$ and its product, phosphatidic acid, mediate agonistdependent raf-1 translocation to the plasma membrane and the activation of the mitogen-activated protein kinase pathway. J. Biol. Chem. 274: 1131-1139.

29. Xavier R, Brennan T, Li Q, McCormack C, Seed B. (1998) Membrane compartmentation is required for efficient $\mathrm{T}$ cell activation. Immunity 8: 723-732.

30. Solomon KR, Mallory MA, Finberg RW. (1998) Determination of the non-ionic detergent insolubility and phosphoprotein associations of glycosylphosphatidylinositol-anchored proteins expressed on T cells. Biochem. J. 334: 325-333.

31. Janes PW, Ley SC, Magee AI. (1999) Aggregation of lipid rafts accompanies signaling via the $\mathrm{T}$ cell antigen receptor. J. Cell. Biol. 147: 447-461.

32. Fra AM, Williamson E, Simons K, Parton RG. (1994) Detergent-insoluble glycolipid microdomains in lymphocytes in the absence of caveolae. J. Biol. Chem. 269: 30745-30748.

33. Simons $M$, Friedrichson T, Schulz JB, Pitto $M$, Masserini $M$, Kurzchalia TV. (1999) Exogenous administration of gangliosides displaces GPI-anchored proteins from lipid microdomains in living cells. Mol. Biol. Cell. 10: 3187-3196.

34. Hooper NM, Turner AJ. (1988) Ectoenzymes of the kidney microvillar membrane. Differential solubilization by detergents can predict a glycosyl-phosphatidylinositol membrane anchor. Biochem. J. 250: 865-869.

35. Deckert M, Ticchioni M, Mari B, Mary D, Bernard A. (1995) The glycosylphosphatidylinositol-anchored CD59 protein stimulates both $\mathrm{T}$ cell receptor zeta/ZAP-70-dependent and -independent signaling pathways in T cells. Eur. J. Immunol. 25: 1815-1822. 
36. Korty PE, Brando C, Shevach EM. (1991) CD59 functions as a signal-transducing molecule for human $\mathrm{T}$ cell activation. J. Immunol. 146: 4092-4098.

37. Montixi C, Langlet C, Bernard AM, et al. (1998) Engagement of $\mathrm{T}$ cell receptor triggers its recruitment to low-density detergent-insoluble membrane domains. Embo. J. 17: 53345348.

38. Stulnig TM, Berger M, Sigmund T, Raederstorff D, Stockinger $\mathrm{H}$, Waldhausl W. (1998) Polyunsaturated fatty acids inhibit $\mathrm{T}$ cell signal transduction by modification of detergentinsoluble membrane domains. J. Cell. Biol. 143: 637-644.

39. Mukherjee S, Soe TT, Maxfield FR. (1999) Endocytic sorting of lipid analogues differing solely in the chemistry of their hydrophobic tails. J. Cell. Biol. 144: 1271-1284.

40. Nguyen DH, Hildreth JE. (2000) Evidence for budding of human immunodeficiency virus type 1 selectively from glycolipid-enriched membrane lipid rafts [In Process Citation]. J. Virol. 74: 3264-3272.

41. ter Haar E, Harrison SC, Kirchhausen T. (2000) Peptide-ingroove interactions link target proteins to the $\beta$-propeller of clathrin [see comments]. Proc. Natl. Acad. Sci. USA 97: 10961100.

42. Dell'Angelica EC, Klumperman J, Stoorvogel W, Bonifacino JS. (1998) Association of the AP-3 adaptor complex with clathrin. Science 280: 43 1-434.

43. Maizel A, Bensaude O, Prochiantz A, Joliot A. (1999) A short region of its homeodomain is necessary for engrailed nuclear export and secretion. Development 126: 3183-3190.
44. Tomoda K, Kubota Y, Kato J. (1999) Degradation of the cyclin-dependent-kinase inhibitor p27Kipl is instigated by Jabl [see comments]. Nature 398: 160-165.

45. Moffett S, Brown DA, Linder ME. (2000) Lipid-dependent targeting of $\mathrm{G}$ proteins into rafts. J. Biol. Chem. 275: 21912198.

46. Martens JR, Navarro-Polanco R, Coppock EA, et al. (2000) Differential targeting of Shaker-like potassium channels to lipid rafts. J. Biol. Chem. 275: 7443-7446.

47. Bruckner K, Pablo Labrador J, Scheiffele P, Herb A, Seeburg PH, Klein R. (1999) EphrinB ligands recruit GRIP family PDZ adaptor proteins into raft membrane microdomains. Neuron 22: $511-524$.

48. Krauss K, Altevogt P. (1999) Integrin leukocyte functionassociated antigen-1-mediated cell binding can be activated by clustering of membrane rafts. J. Biol. Chem. 274: 3692136927.

49. Cheng PC, Dykstra ML, Mitchell RN, Pierce SK. (1999) A role for lipid rafts in B cell antigen receptor signaling and antigen targeting. J. Exp. Med. 190: 1549-1560.

50. Gaulin JF, Fiset A, Fortier S, Faure RL. (2000) Characterization of $\mathrm{Cdk} 2$-cyclin $\mathrm{E}$ complexes in plasma membrane and endosomes of liver parenchyma. Insulin-dependent Regulation [In Process Citation]. J. Biol. Chem. 275: 1665816665.

51. Uren A, Jakus J, de Mora JF, et al. (1997) Carboxyl-terminal domain of p27Kipl activates CDC2. J. Biol. Chem. 272: 2166921672 . 